\title{
Association between ABO Blood Group and Radiographic Findings in Periodontal Disease
}

\author{
Zainab M. Al-Bahrani \\ Lecturer, University of Baghdad, College of Dentistry, Department of Oral Diagnosis, Baghdad-Iraq
}

\begin{abstract}
Background: Periodontal disease is one of the most common diseases in the oral cavity that may be influenced by the blood grouping system among individuals. The purpose of this study was to determine whether there was an association between radiographic findings and $\mathrm{ABO}$ blood groups in patients with periodontal diseases.
\end{abstract}

Material and Method: A prospective study carried out on 200 subjects (99) male and (101) female, aged (18 to 65) who diagnosed clinically with periodontitis who were requested for panoramic and were asked for $\mathrm{ABO}$ blood group and $\mathrm{Rh}$ factor determination. The subjects were divided into two groups according to these findings, as those with (localized chronic periodontitis) and (generalized chronic periodontitis). The association between blood groups and periodontal health were investigated.

Result: There is more predominance of the localized chronic periodontitis (60\%) of subjects. The distribution periodontitis with different blood group of the study population $(41 \%, 30 \%, 20 \%$ and, $9 \%)$ of blood group O followed by B, A, AB respectively. There is more predominance of subjects with Rh positive group (86.5\%) The association between $\mathrm{ABO}$ and $\mathrm{Rh}$ with age groups and with gender were found to be statistically not significant, whilethe association between both localized and generalized chronic periodontitis and Rh factor was a significant.

Conclusion: The association between periodontal diseases and blood group show the high risk people to determine a perfect treatment plan strategy.

Keywords: $A B O$, Rh factor, Periodontal disease, Radiographic findings.

\section{Introduction}

ABO blood group is considered one of the most investigated system that has been utilized as genetic markers to study the relations with many diseases. ${ }^{(1,2)}$ Although several studies have been carried out to investigate relationships between the ABO blood group and the incidence of certain diseases like duodenal ulcer, gastric ulcer and gastric carcinoma, ischemic heart disease and atherosclerosis, little investigation

\footnotetext{
Corresponding Author:

Zainab M. Al-Bahrani

Lecturer, University of Baghdad, College of Dentistry, Department of Oral Diagnosis, Baghdad-Iraq

e-mail: zainab_albahrany77@yahoo.com
}

has been made to explore the relationships between ABO blood groups and the incidence of oral and dental diseases. ${ }^{(3,4,5)}$ The ABO blood types have used by anthropologists as a guide to investigate the modern humans development. The other important blood system is the Rhesus ( $\mathrm{Rh}$ ) system; this system is determined by the nature of different proteins present on the surface of erythrocytes. ${ }^{(6)}$

Periodontal diseases have the high incidence among population. It is the main cause of teeth loss in later adult life. The main extrinsic etiologic factor in periodontal diseases is bacterial plaque, but many studies are carried out to assess whether there is a relationship between $\mathrm{ABO}$ blood groups and periodontal diseases in addition to other factors such as gender, age, education level, smoking habits through simple analysis and research methodology. $(7,8,9)$ 
Radiography plays an integral role in the assessment of periodontal disease. Periodontitis examination is incomplete without accurate radiographs. An overall assessment of periodontal disease is based on both the clinical and radiographic findings whether in localized or generalized periodontitis that is characterized by pocket formation, gingival recession, evidence of alveolar boneloss, furcation involvement. The radiography role is not only in the diagnosis aspect,but in guiding periodontal treatment planningdecisions. ${ }^{(10)}$ Panoramic radiograph of optimal quality is proposed as an alternative radiographicview to the full mouth intraoral survey, and may offer a dose advantage over large numbers of intraoral radiographs. $(10,11)$

\section{Material and Method}

The present investigation was carried out on (200) subjects, (99) male and (101) female, aged (18 to 65) who diagnosed clinically with periodontitis at faculty of dentistry/university of Baghdad in 4 months duration with inclusion criteria : (All subjects should be dentate with no history of any systemic disease, no smoking, they had nearly equal socio-economic level) they were asked for their consent to participation after full explanation about the method and purpose of the study, then they were requested for radiographicinvestigation using panoramic x-ray unit (Planmeca Romexis device) with scanning parameter. $\mathrm{kVp}(60.0 \mathrm{KV}), \mathrm{s}$ (18.35), mA(0.4). Any image with poor quality was excluded from this study. All subjects were asked for ABO blood group and $\mathrm{Rh}$ factordetermination with detailed consent form.

The panoramic images were carefully interpreted for the evidence of radiographic bone loss (vertical and/ or horizontal bone loss) at least in one site, furcation involvement; alveolar crest level that is greater than $2 \mathrm{~mm}$ below CEJ, and periodontal pockets depth more than $4 \mathrm{~mm}$, then the subjects were divided into two groups according to these findings as those with (localized chronic periodontitis) and (generalized chronic periodontitis). The association between blood groups and periodontal health were investigated separately and all data were analyzed statistically.

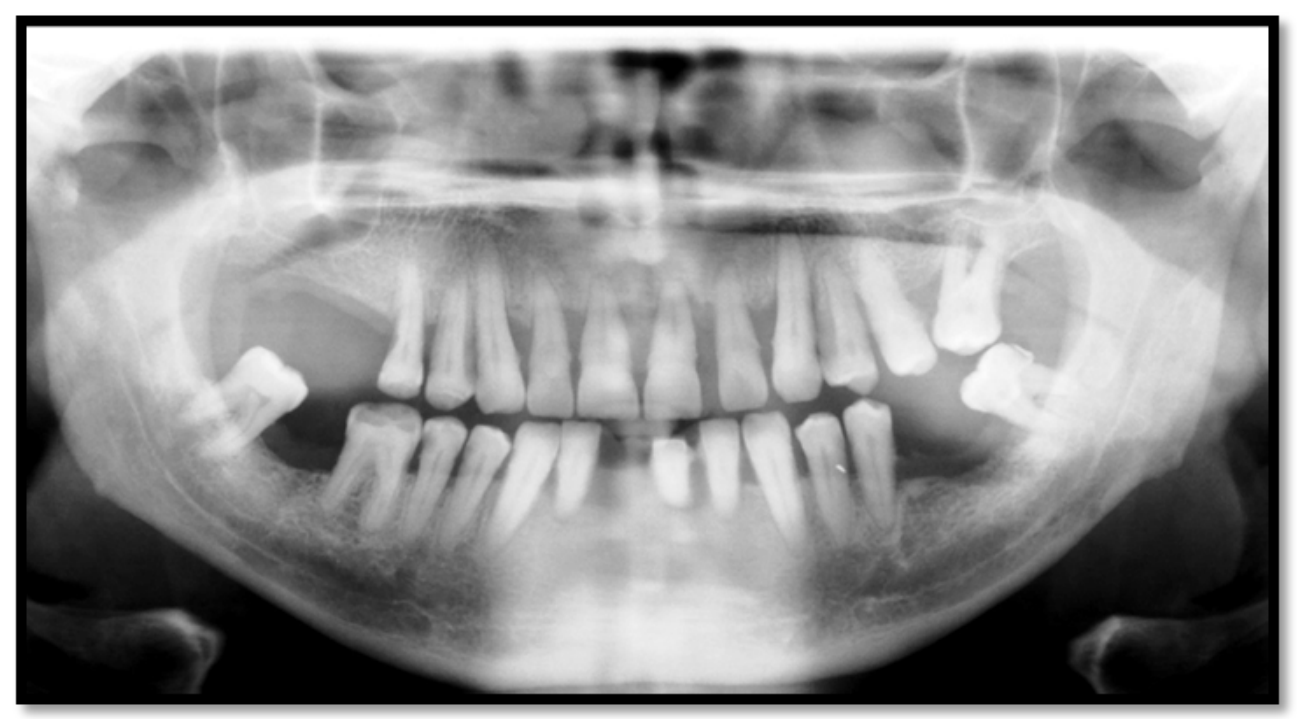

Figure 1: Generalized chronic periodontitis in (AB) blood group patient. 


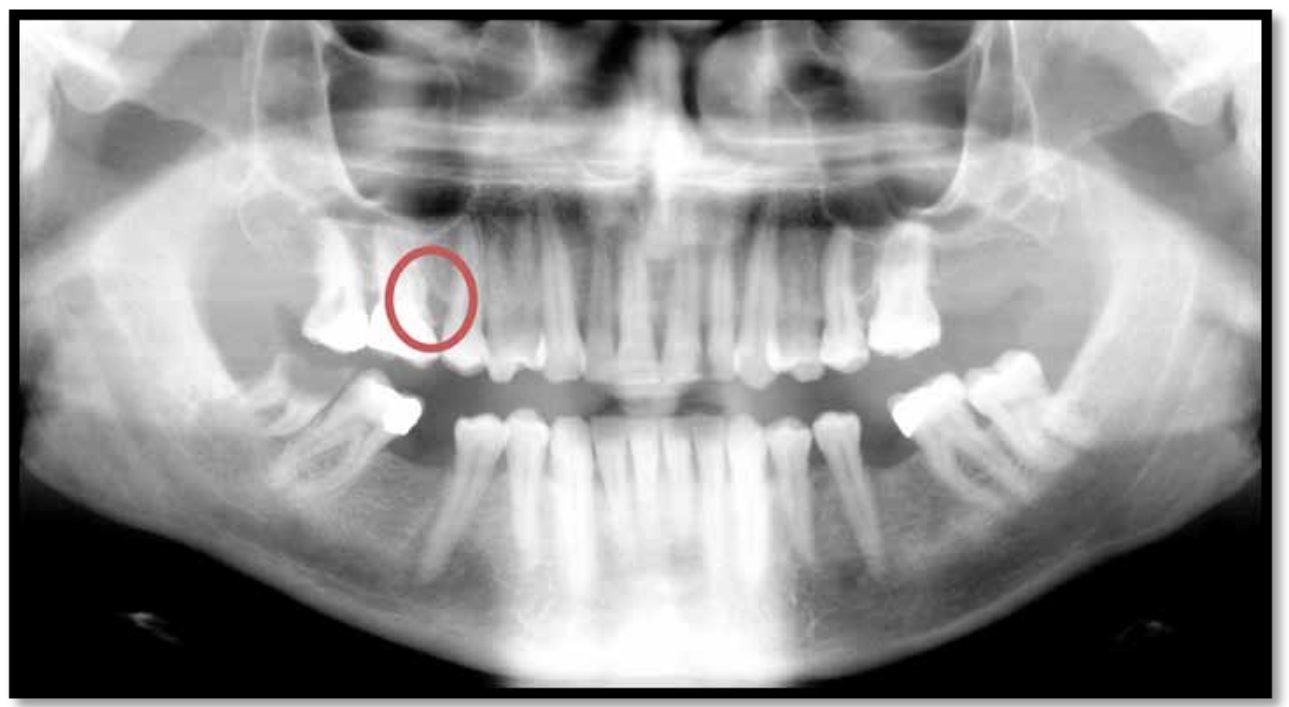

Figure 2: Vertical bone loss in (O) blood group patient.

\section{Result}

Out of the total 200 subjects, 99 were males (49.5\%) and 101 were females (50.5\%).the mean age was $(37.29 \pm 11.05)$ years. There is more predominance of the localized chronic periodontitis $(60 \%)$ of subjects, while the generalized chronic periodontitis found inonly $(40 \%)$.

The distribution periodontitis with different blood group of the study population was observed in $41 \%$ individuals of blood group $\mathrm{O}$ followed by $30 \%$ study participants of blood group B, 20\% of blood group A, and $9 \%$ of blood group $\mathrm{AB}$. There is more predominance of subjects with $\mathrm{Rh}$ positive group (86.5\%) than those with $\mathrm{Rh}$ negative group (13.5\%) and the prevalence of gingivitis was higher in $\mathrm{Rh}$ positive group table (1).

The association between $\mathrm{ABO}$ and $\mathrm{Rh}$ with age groups and with gender were found to be statistically not significant, the significances were as follows: $\mathrm{ABO}$ with age groups (0.196), ABO with gender(0.725), Rh with age groups (0.803), and $\mathrm{Rh}$ with gender groups (0.275).

Table (2) illustrates that both localized and generalized periodontitis were found in blood group $\mathrm{O}$ and $\mathrm{B}$ followed by blood group A while the lowest were found in $A B$ blood group with significant association P-value (0.024).

There was a significant association between both localized and generalized chronic periodontitis and $\mathrm{Rh}$ factor as shown in table(3). It is evident that the total percentage $60 \%$ of the study participants who were localized chronic periodontitis $(\mathrm{Rh}+49.50 \%, \mathrm{Rh}$ $10.50 \%$ ) against $40 \%$ who were generalized chronic periodontitis $(\mathrm{Rh}+37 \%, \mathrm{Rh}-3 \%)$ and this was statistically significant P-value (0.043).

Table 1: Characteristics distribution of the study sample

\begin{tabular}{|l|l|c|c|}
\hline Variables & Categories & No. & \% \\
\hline \multirow{3}{*}{ Age (Years) } & $18-33 y$ & 76 & 38 \\
\cline { 2 - 4 } & $34-49 y$ & 92 & 46 \\
\cline { 2 - 4 } & $50-65 y$ & 32 & 16 \\
\hline \multirow{3}{*}{ Gender } & Males & 99 & 49.5 \\
\cline { 2 - 4 } & Females & 101 & 50.5 \\
\hline \multirow{2}{*}{ Periodentitis } & Localized & 120 & 60.0 \\
\cline { 2 - 4 } & Generalized & 80 & 40.0 \\
\hline
\end{tabular}




\begin{tabular}{|l|l|c|c|}
\hline Variables & Categories & No. & \% \\
\hline \multirow{4}{*}{ ABO } & A & 40 & 20.0 \\
\cline { 2 - 4 } & B & 60 & 30.0 \\
\cline { 2 - 4 } & O & 82 & 41.0 \\
\cline { 2 - 4 } & $\mathrm{AB}$ & 18 & 9.0 \\
\hline \multirow{3}{*}{$\mathrm{RH}$} & $\mathrm{AVE}$ & 173 & 86.5 \\
\cline { 2 - 4 } & -VE & 27 & 13.5 \\
\hline
\end{tabular}

Table 2: Distribution of ABO blood groups among localized a generalized chronic periodontitis patients

\begin{tabular}{|c|c|c|c|c|c|c|c|}
\hline & & \multicolumn{4}{|c|}{ ABO blood group } & \multirow{2}{*}{ Chi-square } & \multirow{2}{*}{ P-value } \\
\hline & & $\mathbf{A}$ & B & $\mathbf{O}$ & $\mathbf{A B}$ & & \\
\hline \multirow{4}{*}{ Localized } & NO. & 30 & 34 & 50 & 6 & \multirow{8}{*}{9.394} & \multirow{8}{*}{0.024 [Sig.] } \\
\hline & $\%$ within Periodentitis & 25.00 & 28.33 & 41.67 & 5.00 & & \\
\hline & $\%$ within $\mathrm{ABO}$ & 75.00 & 56.67 & 60.98 & 33.33 & & \\
\hline & $\%$ of Total & 15.00 & 17.00 & 25.00 & 3.00 & & \\
\hline \multirow{4}{*}{ Generalized } & NO. & 10 & 26 & 32 & 12 & & \\
\hline & $\%$ within Periodentitis & 12.50 & 32.50 & 40.00 & 15.00 & & \\
\hline & $\%$ within $\mathrm{ABO}$ & 25.00 & 43.33 & 39.02 & 66.67 & & \\
\hline & $\%$ of Total & 5.00 & 13.00 & 16.00 & 6.00 & & \\
\hline
\end{tabular}

Table 3: Distribution of Rh factor among localized an generalized chronic periodontitis patients

\begin{tabular}{|c|c|c|c|c|c|}
\hline & & \multicolumn{2}{|c|}{$\mathbf{R h}$} & \multirow{2}{*}{ Chi-square } & \multirow{2}{*}{ P-value } \\
\hline & & $\mathbf{R h}+$ & Rh- & & \\
\hline \multirow{4}{*}{ Localized } & NO. & 99 & 21 & \multirow{8}{*}{4.110} & \multirow{8}{*}{0.043 [Sig.] } \\
\hline & $\%$ within Periodentitis & 82.50 & 17.50 & & \\
\hline & $\%$ within $\mathrm{Rh}$ & 57.23 & 77.78 & & \\
\hline & $\%$ of Total & 49.50 & 10.50 & & \\
\hline \multirow{4}{*}{ Generalized } & NO. & 74 & 6 & & \\
\hline & $\%$ within Periodentitis & 92.50 & 7.50 & & \\
\hline & $\%$ within $\mathrm{Rh}$ & 42.77 & 22.22 & & \\
\hline & $\%$ of Total & 37.00 & 3.00 & & \\
\hline
\end{tabular}

\section{Discussion}

The essential factor in inflammatory periodontal disease is the presence of microorganisms, but the progression of disease is also related to numerous hostbased risk factors, so it consider to be multifactorial in nature. Genetics factors are the most important one. $\mathrm{ABO}$ blood group and Rhesus (Rh)system is the most investigated erythrocyte antigen system. ${ }^{(12)}$

The ABO blood group and Rh system distributions show distinct variation all over the world. This variation may even have existed in different areas within the same country ${ }^{(6)}$ that is explains the various established percentage of $\mathrm{ABO}$ blood group and $\mathrm{Rh}$ system distributions among the study sample. In this study, $41 \%$ of patients were of group $\mathrm{O} ; 30 \%$ were of group B; $20 \%$ were of group A, and only $9 \%$ were of group $\mathrm{AB}$ this proportion was very closed to the $\mathrm{ABO}$ blood distributions in Habeeb et al. study ${ }^{(13)}$ in Iraqi population, Sarhan et al. study ${ }^{(14)}$ in Saudi population, and Agrawal A, et al. study ${ }^{(15)}$ in India they found that the most common blood group was group $\mathrm{O}$ and the lowest was AB group. This study concluded that in the localized periodontitis group a high percentage of 
individuals were observed with O blood group (41.67\% with inperiodontitis) and A blood group (75\% within $\mathrm{ABO}$ ), while in the generalized periodontitis group Similarly, a high percentage distribution of blood group $\mathrm{B}$ and $\mathrm{O}(12.92 \%)$ and a smaller percentage of blood group $\mathrm{AB}(5.12 \%)$ was observed.

This association can be due to various blood groups antigens acting as receptors for infectious agents associated with periodontal disease.

The results of this study regarding $\mathrm{Rh}$ factor showed a significant relationship with localized and generalized chronic periodontitis, Rhfactor distributions was $86.5 \%$ of the study population with Rh-positive and only $13.5 \%$ were Rh-negative. These are in agreement with studies of Moradi and sheikhaddinib, 2016(16), Vivek et al. $2013^{(17)}$, Pai et al., 2012 ${ }^{(18)}$ showed that patients who were Rh-positive were more likely to have periodontitis that mean there is a better periodontal health among the Rhnegative group, but this may be due to the low number of Rh-negative patients in the sample. As a conclusion the association of the $\mathrm{ABO}$ blood groups of patients and the severity of periodontal disease may be important to determine a perfect treatment plan strategies, and it also points toward susceptibility of the subjects with certain blood groups to periodontal disease.

\section{Conflict of Interest: Nil}

\section{Source of Funding: Nil}

Ethical Clearance: This research has exemption as it a routine treatment (no new materials were used).

\section{References}

1. Mourant AE, Kopec AC, Domaniewska-Sobczak $\mathrm{K}$. The distribution of the human blood groups and other polymorphisms. London: Oxford University Press; 1976.

2. Mourant AE, Kopec AC, DomaniewskaSobczak K. Blood groups and diseases: a study of associations of diseases with blood groups and other polymorphisms. London: Oxford University Pres; 1978.

3. Smith A, Athison S, Power E, Abdulla Y. Blood group antigens and Helicobacter pylori infections. Lancet. 1994;343:543.

4. Skripal IG. ABO system of blood groups in people and their resistance to certain diseases (prognosis). Mikrobiol Z 1996; 58(2): 102-108.

5. Suadicani P, Hein HO, Gyntelberg F. Airborne occupational exposure, $\mathrm{ABO}$ phenotype, and risk of obesity. Int J Obes (Lond) 2005; 29(6): 689-696.

6. Ali S. T. Al Ghamdi. Association between abo blood groups and severity of chronic periodontitis. JKAU: Med. Sci. 2009, Vol. 16 No. 3, pp: 31-41.

7. Whaites, E. Essentials of dental radiography and radiology: The periodontal tissues and periodontal disease. $4^{\text {th }}$ Ed. 2007;Edinburgh: Churchill Livingstone Elsevier

8. BalajiR, SheejA S V, AshaR. Relationship between periodontal disease and abo blood group phenotypes-a cross sectional retrospective study. Int J Pharm Pharm Sci, 2015; Vol 7, Issue 11, 386388.

9. Lindhe J, Karring T, Lang NP. Clinical periodontology and implant dentistry, Blackwell Munksgaard. 4. 2003.

10. Vijay G, Raghavan V. Radiography in Periodontics. J Indian Acad Oral Med Radiol 2013; 25(1):24-29.

11. Corbet, E., Ho, D. and Lai, S. Radiographs in periodontal disease diagnosis and management. Australian Dental Journal, 2009; 54: S27-S43.

12. Kinane DF, Bartold PM. Clinical relevance of host responses of periodontitis.Periodontol. 2000;2007:43:278-93.

13. Habeeb B, Jaber H, Ala`a T. Study The Relationship Between ABO Blood Groups And Gingivitis Disease Journal of Kufa for Nursing Science 2014; Vol. (4) No.(1)

14. Sarhan MA, Saleh KA, Bin-Dajem SM. Distribution of ABO blood groups and Rhesus factor in Southwest Saudi Arabia. Saudi Med J 2009; 30(1): 116-119.

15. Agrawal A, et al. $\mathrm{ABO}$ and $\mathrm{Rh}(\mathrm{D})$ group distribution and gene frequency; the first multicentric study in India. Asian J Transfus Sci 2014; 8:121-5.

16. Amirhossein Moradi and Ali sheikhaddinib. Relationship between $\mathrm{ABO}$ blood group and aggressive periodontitis among male students aged 12-18 years in Kermanshah schools, Iran. INT J CURR SCI 2016; 19(2): E 75-82.

17. Vivek S, Jain J, Simon SP, Battur H, Supreetha S, Haridas R. Association of ABO Blood Group and 
$\mathrm{Rh}$ factor with Periodontal Disease in a Population of Virajpet, Karnataka: A Cross-Sectional Study. Journal of International Oral Health 2013;5: 30-4.

18. Pai GP, Dayakar MM, Shaila M, Dayakar A.
Correlation between ABO blood group phenotypes and periodontal disease: Prevalence in south Kanara district, Karnataka state, India. Journal of Indian Society of Periodontology 2012;16: 519-523. 